\title{
Manajemen Mutu Layanan Ta'lim Quran lil Aulad (TQA) di Yayasan Team Tadarus "AMM" Yogyakarta
}

\author{
Supriati H. Rahayu ${ }^{1}$, Hilman Haroen ${ }^{2 *}$, TW Budiutomo ${ }^{3}$, \\ Nginayatul Khasanah ${ }^{4}$, Nuryati ${ }^{5}$ \\ ${ }^{12}$ Universitas Cokroaminoto Yogyakarta, ${ }^{3}$ IKIP PGRI Wates, ${ }^{4}$ \\ IAI Nahdlatul Ulama Kebumen, ${ }^{5}$ STKIP Situs Banten Serang, \\ *Penulis Koresponden, email: hilharun02@gmail.com
}

\begin{abstract}
Abstrak
Penelitian kualitatif tentang mutu layanan akademik pendidikan Quran memiliki kekhususan sesuai karakter material yang mengutamakan tajwid dan tahsin bacaan, khususnya bagi pendidikan TQA yang diselenggarakan oleh Yayasan Team Tadarus Angkatan Muda Masjid dan Musholla (YTT AMM) Kotagede Yogyakarta. Bentuknya pendidikan lanjutan setelah anak-anak belajar di TPA atau TPQ. Namun layanan pembelajarannya juga tidak bisa disamakan dengan para pembelajar Quran tingkat lanjutan bagi usia dewasa yang lebih mandiri. Data yang dianalisis secara secara deskriptif setelah terkumpul melalui observasi, dokumentasi, wawancara mendalam dengan informan yang dilengkapi dengan triangulasi. Penjaminan mutu layanan pembelajaran Quran di TQA telah dijalankan dengan konsisten dalam meningkatkan kualitas Guru. dalam pelayanan Kedekatan para ustaz/ah dengan santri pendidikan TQA menjadi keunggulan yang harusdipelahara dan dikembangkan.
\end{abstract}

Kata kunci: pelayanan, mutu, pendidikan Quran, Ta'lim Quran lil Aulad (TQA)

\section{Abstract}

Qualitative research on the quality of Quran education services has a specificity according to the character of the material that prioritizes recitation and reading recitation, especially for TQA education organized by the Tadarus Team Foundation for the Young Generation Mosque and Musholla (YTT "AMM") Kotagede Yogyakarta. It takes the form of further education after the children study at TPA or TPQ. This requires a specific quality of service in learning for child santri compared to those who are beginners. Academic services are no longer limited to mastering the Iqro book as an important reference for learners at the beginner level at TPA "AMM". However, the learning services cannot be compared to those of advanced Quran learners for more independent adults. The data were analyzed descriptively after being collected through observation, documentation, indepth interviews with informants who were equipped with triangulation. The quality assurance of Quran learning services at TQA has been carried out consistently in improving the quality of teachers. in services The closeness of ustaz/ah with TQA education students is an advantage that must be cultivated and developed. 
Keywords: services, quality, Quran education, Ta'lim Quran lil Aulad (TQA)

\section{Pendahuluan}

Bagi anak-anak Indonesia, pengenalan huruf hijaiyah sebagai dasar baca Quran sangat diutamakan (Imroatun 2017b). Pola yang biasa adalah dengan baca nyaring seperti mereka belajar bahasa nasional (Imroatun 2017a, 2018). Meski demikian, pembelajaran Quran pun tidak bisa sebatas perspektif bahasa Arab sebagai alat komunikasi. Ketentuan ilmu tajwid dalam Quran telah mendorong pembelajarannya perlu perhatian mutu yang lebih bagi pesertanya dibanding pendidikan yang lain. Apalagi pendidikan Quran bagi anak juga termasuk bagian dari pendidikan karakter (Setiani dan Nadjih 2016) dan sangat berpengaruh terhadap kecerdasan spiritualnya (Nuryati Nuryati 2017).

Mutu pendidikan Quran kemudian tidak bisa sebatas pada orientasi yang umum. Namun kenyataan bahwa standar mutu adalah kepuasan pelanggan juga tidak bisa diabaikan. lembaga pendidikan Quran bermutu apabila antara pelanggan internal dan eksternal telah terjalin kepuasan atas jasa yang diberikan. Baku mutunya menjamin pengelolaan dan pelayanan yang mampu mengasilkan pembaca Quran yang berkualitas. Pendidikan yang bermutu berorientasi kepada kepuasan peserta didik (Jalal dan Supriyadi 2001:65).

Mutu bidang pendidikan non-formal yang menonjol untuk dibenahi adalah mutu layanan administrasi dan akademik (Sumiyati 2020). Keduanya ternyata menyangkut semua perangkat sekolah dari pimpinan, guru, karyawan, kebersihan dan keamanan. Artinya, sekolah memang harus memiliki budaya pelayanan yang baik kepada peserta didik dengan tujuan untuk memperolah kepuasan/manfaat atas jasa yang diberikan.

Yayasan Team Tadarus Angkatan Muda Masjid dan Musholla (YTT "AMM") Kotagede Yogyakarta bergerak dalam bidang pendidikan baca tulis Quran melalui metode Iqro yang dikembangkan oleh K.H. Asad Humam (Humam 2000). Lembaga pendidikan non formal Qurani itu telah diakui oleh 
Yusuf (2017)sebagai pembaruan dalam pemberantasan buta baca-tulis al Qur'an tingkat anak dan remaja. Ulfah, Assingkily, dan Kamala (2019) menilai kelebihannya telah dikenal hingga banyak digunakan di kawasan ASEAN.

Sebagai lembaga pendidikan Quran, nama AMM bersama As'ad Humam, pencetus metode Iqro', memang telah harum. Sebagaimana dituturkan oleh Budiyanto di websitenya;

Munas LPTQ yang ke VI tahun 1991 telah menetapkan TKA "AMM" sebagai Balitbang Sistem Pengajaran Baca Tulis A1Qur'an LPTQ Nasional di Yogyakarta (SK LPTQ Nomer: 1 tahun 1991). Setahun kemudian tepatnya pada tanggal 3 Januari 1992, Pemerintah RI melalui Menteri Agama memberikan Piagam Penghargaan kepada KH. As'ad Humam, sebagai Pembina Tilawatil Qur'an di Indonesia. Kemudian bersamaan dengan pembukaan Festival Anak Shaleh (FASI) IV tanggal 11 Juli 1999, di Istana Bogor, Presiden B.J. Habibie berkenan menganugerahkan Piagam Penghargaan kepada $\mathrm{KH}$. As'ad Humam karena kepeloporannya menggerakkan pendidikan Al-Qur'an di Indonesia. Piagam itu telah diterima langsung oleh Ibu Iskilah As'ad Humam (sebagai ahli waris) dari tangan Presiden B.J. Habibie (Budiyanto 2010).

Penelitian ini terfokus pada unit TQA AMM yang setara dengan TKAL dan TPAL sebagai pendidikan Quran lanjutan bagi anak-anak. Tingkatan pembelajaran quran itu bisa dirasakan manfaatnya mengingat banyak bermunculan dimana-mana TKA-TPA akan tetapi belum ada kelanjutannya setelah santri lulus dari TKA-TPA. Padahal selesai TKA TPA dalam membaca Quran belum benar sekali sesuai ketentuan ilmu tajwid atau bacaan tartil yang hanya dilanjutkan dalam TQA.

Animo masyarakat terhadap lembaga TQA AMM semakin tinggi. Seiring waktu berjalan, lembaga mengalami kesulitan dalam hal menyediakan guru (ustaz/ah) berkualifikasi. Bila dibandingkan dengan sebelumnya, minat untuk mengajar di AMM sekarang sangat sedikit. Standar untuk menjadi ustadz/ah AMM persyaratannya memang telah terstandar, ustaz/ah harus memiliki Syahadah 1 (S1) (Budiyanto 2008).

Hal demikian tentu berpengaruh kepada mutu layanannya. Menurut Penelitian Susmiarti mengungkapkan aktifitas-aktifitas TPA Yayasan Team 
Tadarus AMM pada periode 2007-2010 ditinjau dari aspek manajemennya. Dalam kesimpulannya dijelaskan bahwa aktifitas yang berjalan pada TPA tersebut telah berjalan atau terealisasikan sesuai dengan visi misi pengembangan planning, organizing, actualing, dan controlling. Mulyani meneliti Manajemen Pelatihan Ustadz-Ustadzah TKA-TPA di lokasi yang sama dimana tekanannya malah pada teknik dan aktifitas pelatihan dibanding proses organisasi dan tata kelolanya. Sementara Hairiyah juga telah meneliti manajemen terpadu di TKA/TPA AMM . Noor juga meneliti di TQA AMM dengan membandingkan secara kualitatif hasil manajemen TQA dari tiga sistem yang diberlakukan, yaitu TQA sistem pembelajaran tartibiyah (tertib berurutan), TQA sistem maudhu'iyah (modul), dan TQA sistem maddah hifdziyah (kajian materi hafalan) yang dipengaruhi dengan media pembelajaran Quran yang digunakan (Noor 2019).

Dengan penonjolan mutu layanan yang berbasis pada keutamaan tajwid dan tahsin bacaan memerlukan mutu layanan yang spesifik dalam pembelajaran untuk para santri anak-anak dibanding mereka yang pemula. Layanan akademik tidak lagi sebatas penguasaan buku Iqro sebagai rujukan penting bagi para pembelajar di tingkat pemula di TPA "AMM". Namun layanan pembelajarannya juga tidak bisa disamakan dengan para pembelajar Quran tingkat lanjutan bagi usia dewasa yang lebih mandiri (Rahayu et al. 2019).

\section{Metode Penelitian}

field research berjenis kualitatif yaitu berusaha mendeskripsikan dan menganalisis proses mutu akademik Pendidikan Quran di TQA AMM dalam perspektif TQM secara alamiah. Dengan Analisis deskriptif yang demikian, maka tidak digunakan di dalamnya upaya intervensi dari peneliti yang biasa terjadi dalam penelitian tindakan kelas (Prihantoro dan Hidayat 2019). Selain pengamatan pada saat proses pelaksanaan pendidikan tanpa keterlibatan langsung dari peneliti dan dokumentasi digunakan untuk memperjelas data profil, organisasi sekolah, data tentang pengelolaan pendidikan Quran di situ. interview diarahkan kepada para informan terpilih. Mereka adalah Pengurus yayasan, Direktur TQA, ustadz/ah, staf administrasi, dan wali santri yang 
merupakan salah satu pelanggan dari lembaga tersebut. Langkah penting dalam kualitatif adalah triangulasi yang berguna dalam pengumpulan data yang bersifat menggabungkan dari berbagai teknik pengumpulan data dan sumber data yang telah ada (Sugiyono 2012:330). Analisis data melalui model Miles-Huberman. Model ini memberikan langkah-langkah berikut: data reduction (reduksi data), data display (penyajian data), dan conclusion drawing (kesimpulan)/verification (Sugiyono 2012).

\section{Implementasi Mutu Layanan Pembelajaran di TQA}

Persiapan belajar

Tenaga pendidik yaitu guru ustaz/ah, termasuk direktur ikut bertanggung jawab atas tercapainya target silabus tersebut, namun yang paling bertanggung jawab padasini adalah wali kelas, karena wali kelas adalah pemimpin kelas yang bertanggung jawab atas jalannya pembelajaran pada kelas. Maka dari itu wali kelas harus untuk selalu aktif dalam memantau perkembangan santri, dari pembelajaran sampai pada evaluasinya. Tidak jauh berbeda dengan TKAL-TPAL, di setiap kelas unit TQA terdiri dari 2 guru. Untuk menjaga mutu akademis, para guru pada AMM selalu mengadakan sima'an Al-Qur'an setiap 1 bulan sekali dengan tujuan untuk mengasah bacaan para ustadz/zah.

Perlu diketahui bahwasannya pada TQA ada 2 jurusan, pertama: Tahfidz Juz Amma dan ke dua Mauduiyyah (Budiyanto 2008; Noor 2019). Pada setiap jurusannya dibagi menjadi 2 (dua) kelompok belajar yaitu: kelompok belajar Ahad grup dan Sabtu group, dimana dalam setiap grup hanya ada 3 (tiga) hari pertemuan Ahad group meliputi : hari Selasa, Kamis dan Ahad, sedangkan Sabtu grup yaitu : hari Senin, Rabu dan Sabtu. Dimana dalam setiap grup ada 1 guru /wali kelas masing-masing. Untuk tenaga pengajar yaitu ada 1 guru wali kelas dan 1 guru pendamping (misalnya; saat ahad grup masuk, wali kelasnya yang memimpin kelas, sedangkan wali kelas sabtu grup itu pendamping saja, demikian pula sebaliknya). Tugas wali kelas disini juga untuk melaporkan perkembangan santri yang dibentuk dalam forum rapat bulanan. 
Rapat semua guru tersebut dipimpin oleh direktur. Pembahasannya biasa berkisar tentang pencapaian target yang telah dicapai santri dalam proses belajar mengajar, apakah sudah mencapai target atau belum, selain itu juga dalam rapat akhir bulan tersebut biasanya membahas tentang masingmasing perkembangan santri ataupun permasalahan-permasalahan yang telah padahadapi pada setiap kelas masing-masing, misalnya ada anak yang tidak pernah berangkat selama 1 bulan atau bisa japada dalam satu bulan hanya berangkat 2-5 kali, itu suatu masalah yang dimana solusinya biasanya wali kelas bekerjasama dengan direktur memberitahukan langsung kepada wali santri, begitu juga dengan kasus anak yang lambat, masih terbata-bata. biasanya dalam forum rapat itulah banyak mendapatkan solusi baik dari padarektur dan juga masing-masing guru, rapat tersebut terbuka baik untuk direktur dan masing-masing guru semuanya boleh berpendapat.

Materi atau bahan pembelajaran pada TQA AMM dipilah menjadi dua macam, yaitu materi pokok dan materi penunjang. Pemberitahuan tentangnya diberikan ke wali santri di tiap awal bulan pendidikan. Materi pokoknya adalah; pemahaman isi Quran dan hadis berkaitan dengan aqidah, ibadah dan akhlak; penguasaan dasar-dasar Quran; ilmu tajwid termasuk irama murotal dan pengkhataman tadarus Quran berikut hafal terjemahnya.

Materi penunjang masih beragam meski mendukung terhadap kefasihan dan kefahaman terhadap Quran. Bentuknya antara lain; pengenalan semua jenis salat sunah termasuk salat jenazah; memahami terjemah hafalan Quran tingkat TKA-TPA; mengenal dasar-dasar bahasa arab dan penulisannya (khatt) serta hafal mahfudat.

Sebaga catatan; baca surat-surat pendek telah ditekankan dalam penggunaan irama ross (lagu) dari irama 1-5. Dengan target pembelajaran seperti itu, guru dituntut untuk; a) Fasih membaca Quran; b) Dapat membaca Quran dengan menggunakan irama ross $1-5$, c) Hafal dengan fasih pada materi-materi belajar; d) Mampu dalam penulisan ayat-ayat Quran

Materi kedua berbentuk mauduiyyah (modul) yang tersusun dalam sebuah paket belajar berjumlah 40 modul dengan tema-tema tertentu. Noor menilai modulnya lebih lengkap bila dibandingkan dengan TQA dalam 
system pembelajaran Quran lainnya (Noor 2019). Tiap modul berisi rangkaian materi; a) syakal dan membaca dengan maksud agar santri mampu memberi syakal /tanda baca, semakin fasih bacaannya dan dapat membaca dengan irama murotal. b) terjemah lafdziyah sehingga peserta ngaji mampu menerjemahkan kata demi kata dan hafal, dapat memenggal ayat secara tepat, mengenal bahasa arab sebagai bahasa Al-Qur'an dan dapat menulis atau menyalin Quran. c) Terjemah lengkap padamana agar santri memahami terjemah ayat yang bersangkutan padasini santri tidak padatuntut untuk hafal. d) Keterangan agar santri mampu memahami keterangan ayat yang bersangkutan, memiliki wawasan keislaman yang luas.e)Evaluasi tujuannya agar mengetahui tingkat pengertian santri.f) Kajian ilmu tajwid (Budiyanto 2008; Noor 2019)

Sedangkan untuk sistem Tahfidz jus amma (TJA) dinamakan TQA sistem tahfidz juz amma. Sebagai syarat kelulusan minimal, santri harus hafal An-Nas sampai Al-Buruj. Untuk tahfidz juz Amma pada setengah jam pertama, tepatnya 4 hari setiap hari sabtu, ahad, senin dan selasa fokus pada juz Amma, sedangkan Rabu-Kamis tadarus Al-Qur'an juz 20-30. Hafal minimal 30 surat dari 37 surat (Juz 30) selama 1 tahun (Budiyanto 2008). Kegiatan Belajar Mengajar (KBM) pada akhiri dengan Jama'ah Sholat Ashar dan wajib padaikuti oleh semua santri. Santri putri selalu membawa mukena Pelaksanaan pembelajaran

Alokasi waktu/ dalam pengelolaan kelas sebagai usaha dari penanggung jawab kegiatan belajar mengajar atau yang membantunya dengan maksud agar tercapai suatu konpadasi optimal sehingga terlaksana kegiatan belajar mengajar tercapai dengan yang padaharapkan. Selanjutnya Dzamarah dan Zaim secara sederhana mendefinisikan pengelolaan kelas sebagai kegiatan pengaturan kelas untuk kepentingan pengajaran (Suwardi 2007:61).

Di tiap kelas TQA terdapat 17-28 santri,. Sedangkan untuk guru (ustadz/ustadzah) dalam setiap kelasnya ada 2 guru, terdiri dari 1 guru wali kelas dan 2 guru pendamping. Tugas guru wali kelas adalah bertanggung jawab atas terlaksananya program pembelajaran dan perkembangan kondisi 
santri. Sedangkan tugas pendamping, membantu wali kelas dalam proses pembelajaran. Hal demikian dimaksudkan agar siswa mendapat metode pembelajaran yang efektif dan efisien dalam menguasai materi belajar. Semuanya telah mengikuti apa yang dijelaskan oleh Suwardi tentang pengertian metode pembelajaran (Suwardi 2007:126-29).

Proses pembelajaran berjalan selama 90 menit. 5 menit pertama berupa pembukaan untuk mengkondisikan anak supaya siap belajar. Guru biasanya menggunakan kata santrii, anak menjawab siiaap, anteng-antengan ora gojekan sleep, tepuk satu, dan lain sebagainya tergantung kreatifitas dari guru untuk mengarahakn konsentrasi santri pada pelajaran. Ketika anak sudah anteng, guru mengucapkan salam.

15 menit sesudahnya berisi pembelajaran klasikal bagi materi pokok. Setelah guru membuka kelas, maka guru mengajak anak untuk menghafalkan materi yang menjadi pokok bahasan wajib per bulannya, seperti Al-Buruj atau At-Tin. Maka pertama-tama guru menjelaskan pokok bahasan terlebih dahulu materi apa yang dihafal atau target materi yang harus hafal. Setelah itu guru membacakan per-ayat berulang-ulang hingga terampil dan benar, sedangkan anak menirukan guru hingga anak bisa melafaz ayat yang telah dibacakan.

Untuk kelas modul, pembelajaran dibedakan secara klasikal dan privat. Dalam belajar klasikal tulis, santri bersama-sama meng-harakati tergantung tema bulannya. Sedang klasikal baca, anak membaca pertama dengan menggunakan Al-Qur'an dengan aba-aba dari guru dalam mencari surat dan ayatnya. Sebagai persiapan, santri selalu dihimbau untuk selalu menyelesaikan modulnya seperti meng-harakat dari rumah, dan anak belajar memenggal dari berbagai ayat, misalnya yaa ayyuha artinya wahai dan lainlain.

Santri selanjutnya belajar selama 40 menit secara privat. Privat ini cenderung sama dengan belajar Quran secara sorogan (Musodiqin, Nadjih, dan Nugroho 2017) pertama-tama anak membaca pada depan guru, sedangkan guru menyimaknya untuk privat modul TJA, anak menyetorkan hafalan yang sudah padahafalkan atau yang menjapada materi pokok seperti bulan pertama surat Al-Buruj, maka anak menyetorkan surat Al-Buruj, 
biasanya anak yang cerdas yang sudah hafal surat-surat pendek pada rumah, japada anak yang cerdas tersebut tidak mengikuti prosedur hafalan yang padaajarkan pada kelas, sampai saat ini sudah ada satu anak yang sudah sampai surat An-Nazi'at japada tinggal satu surat lagi anak tersebut sudah selesai. Untuk materi privat modul (mauduiyyah), menyetorkan terjemahan yang ada pada modul dengan cara guru menutupi terjemahannya.

Selama ini ada dua metode pembelajaran yang dirasa efisien dan efektif selama pembelajaran privat. Musyafahah atau adu lidah (Syarifuddin 2004:81). Pertama-tama guru membacakan materi yang dipelajari. Misal, surat Al-Ikhlas, guru membacakan terlebih dahulu lalu santri menirukan dengan melihat gerak gerik bibir guru saat ucap atau baca. Disini guru dapat menerapkan cara dengan membaca huruf yang benar melalui lidahnya, sedangkan anak bisa menyaksikan langsung praktik keluarnya huruf dari lidah guru untuk ditirukan. Biasanya guru mengulang-ulang hingga tiga kali setelah itu anak diminta menirukan secara berulang-ulang. Cara kedua terdiri ard qira'ah atau setoran bacaan. Cara demikian juga dikenal dengan sorogan (Musodiqin et al. 2017). Pertama-tama anak membaca pada depan guru, sedangkan guru menyimaknya, anak membaca Quran (modul atau maknanya) perorangan (privat).

Pada 25 menit sebelum santri mengakhiri belajar diberikan materi penunjang secara klasikal. Untuk melancarkan hafalan anak-anak tiap harinya sebelum proses belajar-mengajar pada tutup biasanya guru mengajak anak untuk mengulangi materi hafalan yang tapada telah disampaikan, untuk mengulang-ulang kembali. Terkadang guru tidak selalu monoton untuk menyampaikan materi atau menyuruh anak untuk menghafalkan surat-surat, guru biasanya melihat situasi dan konpadasi anak, terkadang juga guru memberikan tanya jawab seputar materi yang telah dipelajari kepada anak, tujuannya agar anak ingat, seperti melanjutkan surat, atau menterjemahkan surat.

Pada 5 menit terakhir, santri mengikuti penutupan proses belajar. Acara ini dipandu sepenuhnya oleh ustaz/ah. Prosesnya dengan 
mengucapkan syukur alhamdulillah dan salam. Anak-anak santri kemudian keluar secara berbaris urut sembari salim tangan dengan para ustaz/ah Evaluasi Pembelajaran

Evaluasi pembelajaran TQA AMM agak berbeda dengan unit pemula. Pertama, evaluasi hafalan dengan: menyetorkan hafalan yang sudah hafal yang menjadi pokok wajib setiap harinya. Untuk evaluasi (modul) merangkap dari berbagai modul yang ada, seputar yang ada pada setiap tema modul. Perhatian evaluasi ini pada; tartil dalam irama dan makharijul huruf / kefasihan; Khatt dengan melihat hasil dari masing-masing catatan yang ada pada modul sebelumnya, tulisannya seperti apa dan lain sebagainya; tadarus pada ketepatan tajwid, dan Hafalan berikut pemahaman makna. Kedua, Evaluasi tertulis di setiap akhir semester secara tertulis dari materi yang telah disampaikan pada tiap bulannya.

\section{Mutu Layanan pendidikan Quran TQA}

Ketepatan waktu dan akurasi pelayanan dengan memberikan pelayanan tepat waktu seperti yang disepakati dengan pelanggan. Penundaan waktu dari yang telah disepakati bisa menjadi cacat mutu. Akurasi pelayanan atau ketepatan prosuk/jasa seperti yang diminta pelanggan merupakan salah satu dari ciri mutu pelayanan. Kesalahan atau kemelencengan dari apa yang padapesan, menyebabkan produk/jasa tersebut tidak bermanfaat bahkan mendatangkan kerugian bagi pelanggan. Adapun ketepatan waktu pelayanan santri yaitu dengan ketepatan proses pelaksanaan belajar. Berdasarkan hasil observasi sebagian besar Guru sudah hadir 5 menit sebelum bel berbunyi. Ketepatan waktu layanan juga dapat dilihat dengan pemberian informasiinformasi yang dibutuhkan santri. Misal; jadwal kegiatan belajar mengajar pada satu semester, laporan hasil evaluasi, pemberian materi hafalan bulan berikutnya dan seterusnya.

Kesopanan dan keramahan untuk untuk pembelajaran yang menyenangkan bagi santri. Komunikasi beretika dengan santri dan walinya secara menjadi unsur penting untuk menjaga mutu. Suasana akrab antara guru dan santri telah terjalin, tidak terbatas pada ruang kelas saja. Di luar kelas pun guru senantiasa memberi salam lebih dulu kepada santrinya, 
berjabat tangan, dan menyapanya dengan tersenyum. Semuanya perlu terus dipelihara.

Pertangungjawaban segala keluhan santri. direktur mapun ustaz/ah sebagai penghasil jasa belajar Quran harus berani bertanggung jawab atas segala yang telah diperbuatnya. Semua yang menjadi keluhan (komplain) pelanggan harus pada pertanggungjawabkan. Hal demikian tentu mengedepankan pelayanan pribadi sehingga tidak terkesan kaku, fleksibel dan terkesan ada penanganan khusus bagi santri peserta didik.

Keterlibatan semua pihak internal AMM dalam pendidikan TQA ini telah memberikan manfaat yang besar. Hal itu dikarenakan ustaz/ah, dalam pengertian Syafaruddin dan Irwan Nasution, adalah fasilitator sekaligus manajer pendidikan. Peran ini mensyaratkan sistem yang berbasis sumber daya, penggunaan kekuatan alat-alat baru berkaitan dengan kemajuan teknologi daripada berbasis kepada guru (Syafaruddin dan Nasution 2005:75). Karena itu, Hairiyah menyatakan partisipasi bersama ustaz/ah dan staf di TKA-TPA "AMM" Kotagede Yogyakarta mempunyai manfaat: (1) dapat menghasilkan keputusan yang baik dan perbaikan yang lebih efektif karena pandangan dan pemikiran dari pihak yang langsung berhubungan dengan situasi kerja, (2) meningkatkan "rasa memiliki" dan tanggung jawab atas keputusan dengan melibatkan orang yang harus melaksanakan (Hairiyah 2010:18-21).

\section{Penutup}

Penjaminan mutu pembelajaran Quran di TQA YTT AMM Yogyakarta telah dijalankan dengan konsisten. Dalam meningkatkan kualitas Guru, konsistensinya bisa dilihat dari bentuk penyusunan program pengembangan kompetensi ustaz/ah secara terpadu, baik dari aspek kognitif, afektif maupun psikomotorik. Kerjasama dan komunikasi yang baik dari direktur, staf, ustaz/ah dan karyawan mutlak menunjang keharmonisan. Karena komunikasi adalah senjata yang paling ampuh dalam melakukan kerjasama.

Kedekatan para ustaz/ah terhadap santri pendidikan TQA menjadi keunggulan yang harus dijaga. Bagaimanapun mereka harus dapat 
memahami karakter para siswa, agar menjadikan salah satu pendukung terhadap kelancaran dalam proses pembelajaran Quran yang bermutu yang juga mengandalkan pembelajaran privat. Gunakan kata-kata yang ajaib dalam setiap pembelajaran atau lingkungan pembelajaran, seperti: minta tolong, mohon maaf, ketika melakukan suatu kesalahan terhadap siapapun, karena kata-kata ajaib tersebut akan mendidik karakter siswa menjadi lebih baik. Garis bawah dalam pelaksanaan pembelajaran Quran di TQA adalah Keteladanan ustaz/ah menjadi nomor satu dalam perhatian dan contoh oleh siswa, baik di dalam atau luar pembelajaran pada segala hal.

\section{Daftar Pustaka}

Budiyanto, Mangun. 2008. Paduan Praktis Pengelolaan TKA-TPA, TKAL-TPAL, dan TQA. Yogyakarta: Balai Litbang LPTQ Nasional Team Tadarus "AMM."

Budiyanto, Mangun. 2010. "Pembaruan Metodologi Pembelajaran Membaca Al-Quran (Studi Pemikiran KH. Asad Humam dan Penerapannya di TKA-TPA 'AMM' Kotagede Yogyakarta)." Diambil (https://mangunbudiyanto.wordpress.com/2010/06/21/pembaruanmetodologi-pembelajaran-membaca-al-qur'an-studi-pemikiran-kh-as'adhumam-dan-penerapannya-di-tka-tpa-"amm"-kotagede-yogyakarta/).

Hairiyah. 2010. "Pengelolaan Pendidikan Al-Qur'an Dalam Perpektif Manajemen Mutu Terpadu (Studi kasus di TKA-TPA 'AMM' Kotagede Yogyakarta)." UIN Sunan Kalijaga Yogyakarta.

Humam, Asad. 2000. Buku Iqra, Cara Cepat Belajar Membaca Al-Qur"an, Jilid. I6. Yogyakarta: Balai Litbang LPTQ Nasional Team Tadarus "AMM."

Imroatun, Imroatun. 2017a. "Media Belajar Bigbook Bagi Pengembangan Baca Nyaring Anak Usia Dini." Hal. 119-27 in Prosiding Seminar Nasional Pembelajaran Baca, Tulis, Dan Hitung Tingkat Permulaan Bagi Anak Usia Dini. Serang: PIAUD FTK UIN Sultan Maulana Hasanuddin Banten.

Imroatun, Imroatun. 2017b. "Pembelajaran Huruf Hijaiyah bagi Anak Usia Dini." Hal. 175-88 in Proceedings of The 2nd Annual Conference on Islamic Early Childhood Education. Yogyakarta: Program Studi Pendidikan Islam Anak Usia Dini Fakultas Ilmu Tarbiyah dan Keguruan UIN Sunan Kalijaga Yogyakarta'.

Imroatun, Imroatun. 2018. "Alternatif Media Pengembangan Literasi Baca Tulis Berbahasa Nasional Bagi Siswa Raudlatul Athfal.” Hal. 103-12 in Al Hikmah Proceedings on Islamic Early Childhood Education. tuban: Program Studi PIAUD STAI Al Hikmah Tuban.

Jalal, Fasli, dan Dedi Supriyadi. 2001. Reformasi Pendidikan dakam Konteks Otonomi Daerah. Yogyakarta: Adicita Karya Nusa.

Musodiqin, Muhammad, Difla Nadjih, dan Taufik Nugroho. 2017. "Implementasi Sorogan Dalam Pembelajaran Al-Qur'an Pada Madrasah 
Diniyah Takmiliyah." Ulumuddin: Jurnal Ilmu-ilmu Keislaman 7(1):59-71.

Noor, Fuad Arif. 2019. "Manajemen Ta'limul Qur'an Lil Aulad (TQA)

Dalam Memahami Al-Qur'an." JIEM (Journal of Islamic Education Management) 3(1):38-49. doi: 10.24235/jiem.v3i1.5002.

Nuryati Nuryati. 2017. "Pengembangan Kecerdasan Spiritual Pada Anak Usia Dini Melalui Murottal Bacaan Al Qur'an." As-Sibyan: Jurnal Pendidikan Anak Usia Dini 2(1):17-26.

Prihantoro, Agung, dan Fattah Hidayat. 2019. "Melakukan Penelitian

Tindakan Kelas." Ulumuddin: Jurnal Ilmu-ilmu Keislaman 9(1):49-60.

Rahayu, Supriati H., Hidayatul Huda, Joko Wahono, Difla Nadjih, dan A.

Zain Sarnoto. 2019. "Implementasi Pendidikan Quran Tingkat Lanjut Bagi Santri Usia Dewasa." Nuansa Akademik Jurnal Pembangunan Masyarakat 4(1):63-78.

Setiani, dan Difla Nadjih. 2016. "Pembentukan Karakter Anak Usia Dini Melalui Pendidikan Agama Islam Di TK ABA Kalibulus Rogobangsan Bimomartani Ngemplak Sleman." Ulumuddin: Jurnal Ilmu-ilmu Keislaman $6\left(2^{\prime}\right): 125-36$.

Sugiyono. 2012. Metode Penelitian Pendidikan. Bandung: Alfabeta.

Sumiyati, Sumiyati. 2020. "Pelatihan Soft Skill Untuk Meningkatkan Kualitas

Dan Mutu Layanan Paud Di Desa Ngagel." As-Sibyan: Jurnal Pendidikan Anak Usia Dini 5(1):31-42. doi: 10.32678/as-sibyan.v5i1.2425.

Suwardi. 2007. Manajemen Pembelajaran, Mencipta Guru Kreatif dan Kompetensi. Salatiga: STAIN Salatiga Press.

Syafaruddin, dan Irwan Nasution. 2005. Manajemen Pembelajaran. Jakarta: Quantum Teaching.

Syarifuddin, Ahmad. 2004. Mendidik Anak, Membaca, Menulis, dan Mencintai Al-Quran. Jakarta: Gema insani.

Ulfah, Tsaqifa Taqiyya, Muhammad Shaleh Assingkily, dan Izzatin Kamala. 2019. "Implementasi Metode Iqro Dalam Pembelajaran Membaca AlQuran." TA'DIBUNA: Jurnal Pendidikan Agama Islam 2(2):59-69. doi: 10.30659/jpai.2.2.44-54.

Yusuf, M. Jamil. 2017. "Metode Iqra: Kajian Inovasi Pembelajaran AlQuran." JURNAL EDUKASI: Jurnal Bimbingan Konseling 3(2):209-33. doi: $10.22373 /$ je.v3i2.3097. 
S.H. Rahayu, Hilman Haroen, TW Budiutomo, Nginayatul Khasanah, Nuryati 